\title{
Fire-resistance Rating of Square Steel Tubes and Concrete-filled Square Steel Tubular Columns Protected with Ultra-thin Fire- retardant Coating
}

\author{
ANSHENG WU ${ }^{1}$, BO ZHANG ${ }^{2 *}$, LE TIAN ${ }^{1}$ \\ ${ }^{1}$ Shaanxi Railway Institute, Weinan, Shanxi, 714000, China \\ ${ }^{2}$ Civil Engineering College, University of Jilin Jianzhu, Changchun, Jilin, 130118, China
}

\begin{abstract}
To promote and criterionize the application of ultra-thin the fireproof coating s to building structures, four concrete-filled square steel tubular (CFSST) pillars as well as two square steel tubes, each protected along with ultra-thin the fireproof coating, were subjected to full-scale fire tests to investigate their fireproof level on the basis of the ISO 834 criterion time-degrees curve. Test results revealed not only the temperature variation characteristics of specimens suffered from inconsistent fire exposure, but also effects of the steel ratio of the test specimen and the number of fire-exposed sides on the fire-refractory level of the test specimen. Test results demonstrated that when protected with an ultra-thin the fireproof coating, the heating rate of the specimens was considerably lower than that of the test furnace, suggesting that the ultra-thin the fireproof coating exhibits good thermal insulation performance. The test results were compared with China's current criterions for the fire-refractory level of square steel tubes and CFSST pillars, indicating that the criterions would lead to a relatively conservative fire-safe design for four-side fire exposure.
\end{abstract}

Keywords: ultra-thin the fireproof coating,quadrate steel tube, square steel tubiform pillars;concrete, fireproof level

\section{Introduction}

Square steel tubes and square tubiform columns, which are made of concrete, are commonly applied in the architectural aspect $[1,2]$. However, as steel is exposed to the environment, its strength drops significantly for high fire temperatures, with the structure rapidly losing its bearing capacity and failing to satisfy the requirements for fire-safe design of buildings, this also causes huge loss of human life and property [3-5].

Reasonable fire-safe design can reduce fire-caused damage to building structures [6,7], prevent a dramatic decline in the material intensity of the building structure over a short duration due to high temperatures, and avoid consequent destabilization and destruction of the overall structure, thus, minimizing possible loss of human life and property due to fire and reducing the restoration cost of the building structure after the fire $[8,9]$.

Thus far, several studies have been conducted on fire-resistant properties of columns and a few useful results have been obtained. Wang et al. established a limited-substance model of concrete steel tubiform pillar steel purlin plane frame under fire-exposure conditions [10]. An analysis conducted by Wang et al [10]. demonstrated that when fire is in the same non-top story and the frame column is under the same fire-exposure conditions, the internal force undergoes redistribution in such a manner that the fire-damaged column is under high pressure and thereby has a low fireproof level; when exposed to fire within the same column span in a non-top story, the axial compression proportion of the skeleton pillar is reduced while the fireproof level increases with increasing story [10]. Li et al. studied the influences of various parameters on the fire-proofing level about concrete-filled steel tubular pillars, determining that the fire-proofing level decreased along with increasing axial compression ratio but increased with increasing wall thickness and area of cross section of the steel pipe. Furthermore, the marginal prerequisite to both column ends are equipped with momentous

\footnotetext{
*email: zhang.b781@gmail.com
} 
effects on the fire-proofing rating [11]. Lu et al. conducted a fireproof level test on self-compacting steel pipe made of concrete short pillars beside proposed a limited-substance model to develop the fire activity of the pillars, with an analysis conducted on the configurable performance of the steel pillar such as strain, stress, load distribution, and local buckling under fire-exposure conditions [12]. Chen et al. conducted a fire test on nine reinforced concrete columns at different reinforcement ratios in the light of the ISO 834 criterion time-temperature bight and obtained fire-proofing rating [13]. Zhao et al. stimulated a fire test on special-shaped concrete rectangular steel tubelike (CFRST) pillars covered as aerated lightweight concrete (ALC) panels for thermal insulation; the test results demonstrated that the special-shaped CFRST columns with ALC panels satisfied the specification requirements of grade-1 fire-resistant members, with the heating rate of the fire-resistant panels significantly lower than the heating rate of the furnace, that suggests that ALC panels exhibit good fire-resistant performance [14]. Rush conducted a fire test on reinforced concrete columns and evaluated the damage to the columns, determining that the commonly adopted concept of fire intensity defined by equivalent fire duration could not fully explain the complexity of the changes In terms of mechanical aspects of the concretefilled pillars though the flame [15]. Han et al. [16,17] delivered an laboratorial research on the fireresistant representation about 13 concrete round steel tubiform (CFCST) pillars, 8 CFRST columns, and 3 quadrate steel tubiform (CFSST) columns made of concrete, with the columns divided into test groups including fireproof coating beside control groups without fire-resistant coating; the experiment was conducted under axial load versus eccentric load, and the column core was filled with plain concrete not reinforced with steel bars. The laboratorial outcomes of Han et al. $[16,17]$ demonstrated that the protective coating reduced the heating rate at the cross sections and slowed strength of material loss thereof, thereby improving the fireproof level; the results also indicated that load eccentricity equipped with a momentous influence on the fireproof level, with eccentricity of loads leading to a exterior fireproof level. Hong and Varma [18] conducted a train of theoretical calculations upon fireresistant performance of pillars and conducted a theoretical simulation using finite-element software, with analysis including nonlinear analysis, on temperature field and fireproof level; moreover, they theoretically calculated and analyzed the influencing factors of fireproof level and conducted relevant experiments to verify the theoretical results. Eamon [19,20] analyzed the dependability about reinforced concrete pillars under the circumstances of fire loading and managed a method to contrast the dependability of prestressed columns which made of concrete in case of fire loading conditions. These studies only considered the scenario of four-side fire exposure; however, practically, other conditions such as one-side fire exposure, two-opposite-side fire exposure, and three-side fire exposure may also be present, all moderately different from the four-side fire-exposure condition. Therefore, a decrease in the number of fire-exposed sides would lead to a decrease in heat input to the member and thereby a decrease in its overall temperature compared with four-side fire exposure, resulting in reduced loss of material strength. Thus far, the existing studies have not explored the fire-proofing rating of pillars along with a different combination about sides exposed to fire, and thus, it is essential to manifest in-depth research on building the fireproof coating $\mathrm{s}$.

For fire-safe design, the simplest yet most effective method is to coat building members with fireresistant materials. China's relevant criterions [21] classify the fireproof coating by thickness, namely thick the fireproof coating (coating thickness $>7 \mathrm{~mm}$ but $\leq 45 \mathrm{~mm}$ ), thin the fireproof coating (coating thickness $>3 \mathrm{~mm}$ but $\leq 7 \mathrm{~mm}$ ), and ultra-thin the fireproof coating (coating thickness $\leq 3 \mathrm{~mm}$ ). As a new type of the fireproof coating, ultra-thin the fireproof coating has the advantages of thinness, good decorative effect, and strong adhesion compared with conventional thick the fireproof coating and thin the fireproof coating, and it may realize wide applications in the fire-safe design of various constructions $[22,23]$. However, owing to the high cost of conducting fire tests on the fireproof level of buildings, few China-based studies have been conducted on the application of ultra-thin the fireproof coating to buildings. The specifications of fireproof level are established based on four-side fireexposure conditions and are currently in use; however, specifications for applying ultra-thin the fireproof coating to fire-safe design of buildings are unavailable. As a result, when incorporating ultra- 
thin the fireproof coating in fire-safe design of buildings, the designers tend to be over-conservative to avoid wasteful and excessive use of ultra-thin the fireproof coating. This practice is not beneficial for advocating the use of ultra-thin the fireproof coating, and it lacks in scientific soundness and consistency. Consequently, it contains enormous academic meaning as well as value of practice about studying the flame-resistance rating of buildings with ultra-thin the fireproof coating and establish proper methods for fire-safe design of buildings.

This study conducted fire tests on full-scale square steel tubes and CFSST columns protected with ultra-thin the fireproof coating in line with the ISO 834 criterion time-temperature curve [24], exploring effects about steel ratio (0.1 vs. 0.15$)$ and fire-exposure condition (one-side vs. twoopposite-side) on the fireproof level as well as damage pattern about the test specimen.

\section{Materials and methods}

\subsection{Specimen Project as well as Fabrication}

Factors to consider when designing specimens comprise fire-exposure condition (one-side vs. twoopposite-side) and steel ratio (0.01 with $8 \mathrm{~mm}$ thick steel tube wall vs. 0.15 with $10 \mathrm{~mm}$ thick steel tube wall).

A total of six columns were used as specimens in this study, with specimen parameters enumerated in Table 1, in which $\alpha$ represents the steel ratio $(\alpha=\mathrm{AS} / \mathrm{AC}$, AS is the area of cross-section about the steel pipe,while AC is the area of cross-section about core concrete) and S3 and S4 refer to hollow square steel tubes without concrete. $\mathrm{B}$ and ts are the cross section of side longness and the wall thickness of the steel pipe, respectively. L represents the length involving test specimen, $\lambda$ represents the proportion of slenderness, and $\mathrm{n}$ is the axial compression ratio (equal to 0.6). Hinged boundary conditions were applied to the two ends involving specimen.

Table 1. Parameters of the specimens

\begin{tabular}{|c|c|c|c|c|}
\hline Sample No. & Fire-exposure condition & $B \times \mathbf{t}_{\mathbf{2}}(\mathbf{m m})$ & $L(\mathbf{m m})$ & $\alpha$ \\
\hline S1 & two-opposite-side & $300 \times 10$ & 3700 & 0.15 \\
\hline S2 & two-opposite-side & $300 \times 8$ & 3700 & 0.01 \\
\hline S3 & two-opposite-side & $300 \times 10$ & 3700 & - \\
\hline S4 & one-side & $300 \times 8$ & 3700 & 0.15 \\
\hline S5 & one-side & $300 \times 10$ & 3700 & 0.01 \\
\hline S6 & one-side & $300 \times 8$ & 3700 & \\
\hline
\end{tabular}

Concrete strength was measured using three groups of criterion test blocks $(150 \times 150 \times 150 \mathrm{~mm})$ each contrasted in terms of the identical curing conditions as samples and averaged 52.6 MPa. Axial compression tests were conducted according to procedures specified elsewhere [25].

Steel strength was determined by tensile tests. For each type of steel, three criterion specimens made from steel plates were subjected to yield strength and tensile strength tests according to China's relevant criterions [26], after which the strength of medial yield as well as average tensive strength were calculated and reported (Table 2).

Table 2. Relevant parameters of steel materials

\begin{tabular}{|c|c|c|c|}
\hline No. & Thickness $t_{s}(\mathrm{~mm})$ & Strength of medial yield $f_{y}(\mathrm{MPa})$ & Strength limit $f_{\mathrm{u}}(\mathrm{MPa})$ \\
\hline I & 8 & 344.93 & 506.43 \\
\hline II $^{-}$ & $10^{--}$ & 373.25 & 521.05 \\
\hline
\end{tabular}


The specimens were fabricated using steel according to the design dimensions (Figure 1), with premolded holes (20 $\mathrm{mm}$ and $40 \mathrm{~mm}$ diameter) drilled at positions specified in the blueprint (Figure 1). The $20 \mathrm{~mm}$ pre-formed holes were intended to drain the vapor during the test process to prevent the weld from cracking, and the $40 \mathrm{~mm}$ pre-formed holes were intended to install thermocouples before the tests.

When welding endplates to both ends of the steel tube, welding should be conducted first at the lower end, followed by concreting the upper end, and then welding a second endplate to the upper end. Owing to the considerable height of the specimens, concrete pouring and vibration was conducted in a layer-wise manner to ensure the compaction of the concrete. Before the welding of endplates, cement mortar with high-strength was applied for achieving leveling between the core concrete as well as the end external about the steel pipe such that concrete beside the steel tube would be subjected to the same force when loads are applied.

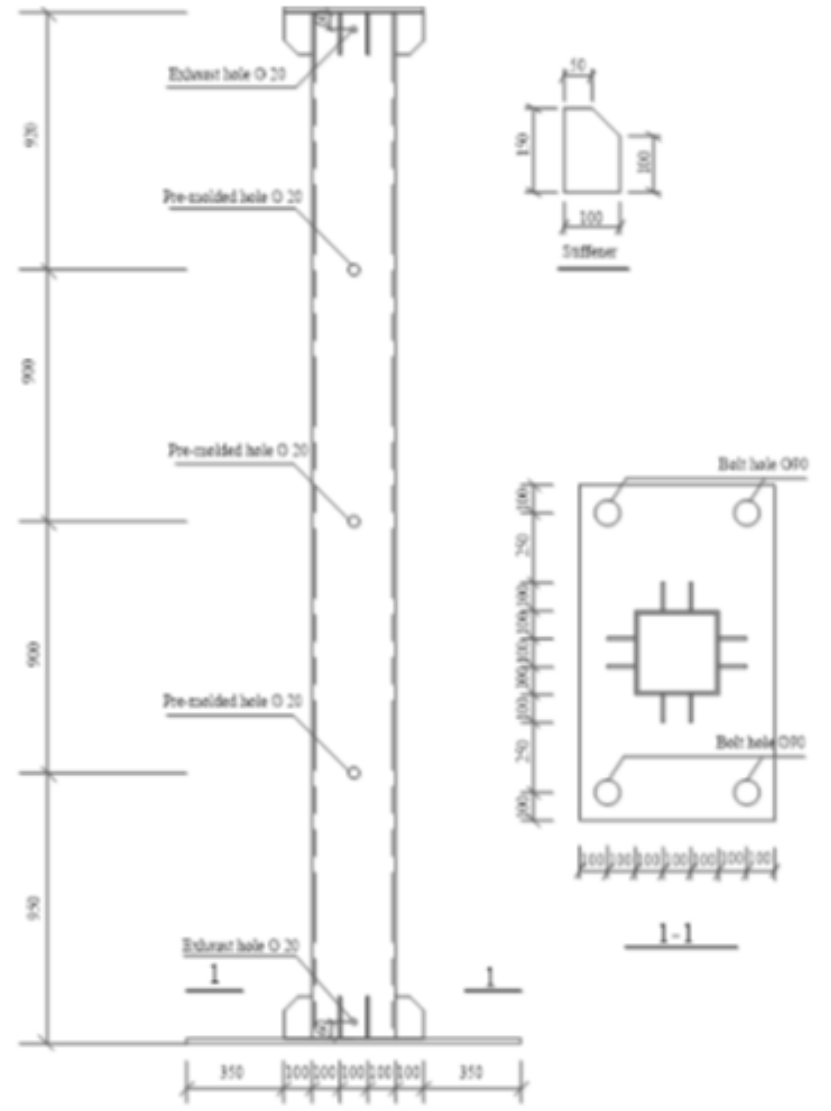

Figure 1. Specimen dimension (mm)

To determine the characteristics of cross-sectional temperature variation of the test specimens, thermocouples were placed at longitudinal positions. Figsure 2(a) and 2(b) present the layout of the thermocouples in the middle of the test specimens, while other panels of Figure 2 present the layout of the thermocouples at both ends of the specimens. More thermocouples were placed in the middle than at the ends. The end thermocouples were intended to verify whether the temperature field in the axial direction of the test specimens was uniform and to prevent data loss due to malfunction of the middle thermocouples. Thermocouples, each protected by a ceramic tube, should be sufficiently long to ensure that they could be safely inserted into the fire test furnace while the remaining parts outside the furnace were connected to compensating wires. For one-side fire exposure, the layout and numbering of thermocouples were the same as for two-opposite-side fire exposure. 


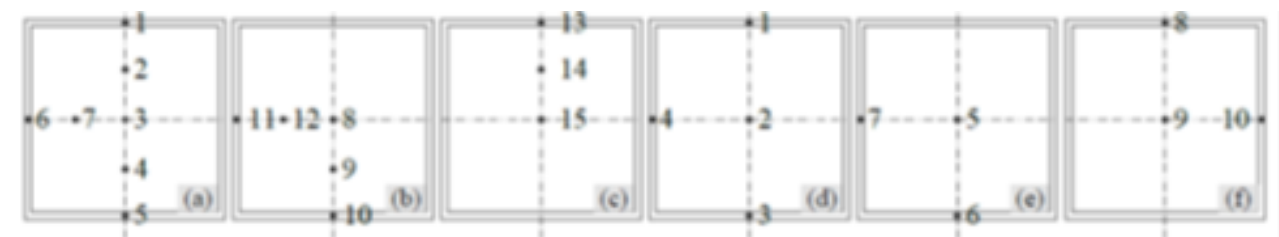

Figure 2. Layout of thermocouples. (a)-(c) refer to the layout of thermocouples for steel tubiform pillars of concrete, and (d)-(f) refer to the layout for hollow steel tubular columns without concrete

As shown in Figure 3 Specimen sides not exposed to fire were covered by two layers $(100 \mathrm{~mm}$ total thickness) of fire-retardant fabric with maximum temperature rating of $1,260{ }^{\circ} \mathrm{C}$. To ensure that the non-fire-exposed sides of the steel tubes were in tight contact with the fire-retardant fabric, it was secured using elevated temperature adhesive involving a range of temperature $1,200{ }^{\circ} \mathrm{C}$ to the utmost, and thermocouple wires.

Table 3. Main components of ultra thin fire retardant coating

\begin{tabular}{|c|c|}
\hline Raw Material & Mass Fraction I\% \\
\hline Emulsion & $22.0 \sim 28.0$ \\
\hline Titania & 9.0 \\
\hline Ammonium Polyphosphate & $20.0 \sim 25.0$ \\
\hline Pentaerythritol & $6.0 \sim 8.0$ \\
\hline Melamine & $5.0 \sim 7.0$ \\
\hline Filler & 1.5 \\
\hline Auxiliary & $2.0 \sim 4.0$ \\
\hline Deionized Water & $23.0 \sim 28.0$ \\
\hline
\end{tabular}

When the structure is affected by the high temperature of fire, the fire retardant coating is softened by heating and melting, ammonium polyphosphate ((NH4PO3)n) is decomposed to phospholipid (H3PO4), phospholipid (H3PO4) catalyzes the fatty reaction of pentaerythritol $(\mathrm{C} 5 \mathrm{H} 12 \mathrm{O} 4)$ to produce viscous fatty product carbon layer; at the same time, the foaming agent melamine (C3H6N6) is decomposed to inert gas $\mathrm{N} 2$ by heating to generate inert gas The gas, together with the coating of viscous fatty product carbonaceous layer and the melt polymerization product carrier, expands together to form a dense and uniform sponge like carbonaceous layer, which slows down the heat transfer inward and plays a role of fire prevention and heat insulation $[22,23]$.

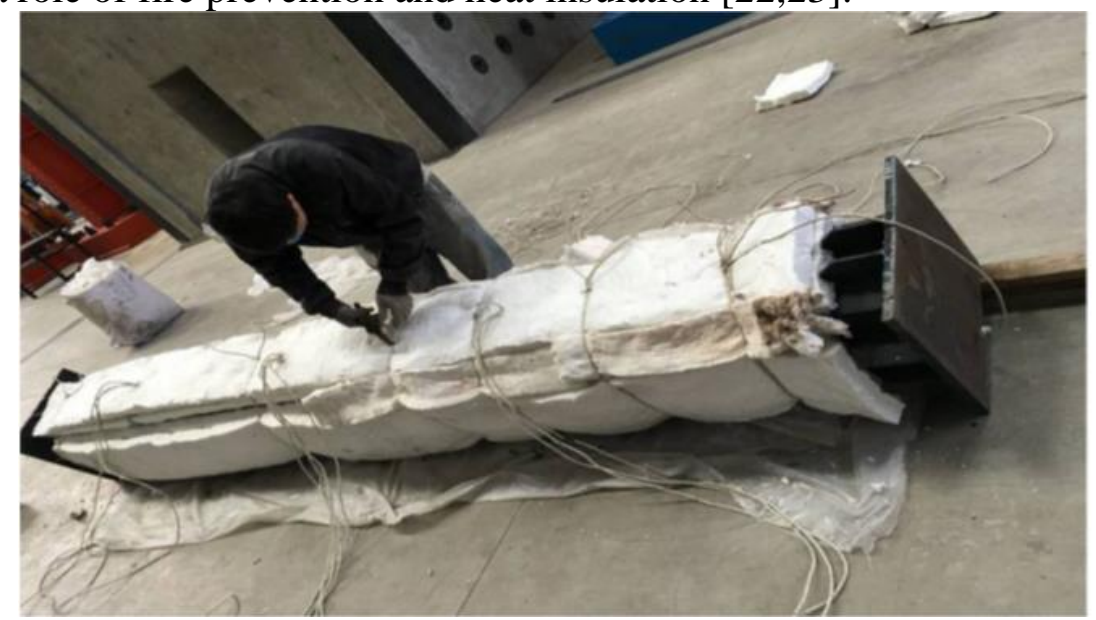

Figure 3. Layout of fire-retardant fabric

In the curing process of CFSST specimens, ultra-thin the fireproof coating ( $3 \mathrm{~mm}$ thickness) was painted using both an airbrush and a paint roller. Each layer of the fire-resistant materials was 
controlled to $\leq 0.5 \mathrm{~mm}$ to avoid cracks on the coating surface. Two consecutive rounds of painting were separated by at least $24 \mathrm{~h}$, and the base layer had to be dry prior to the next round of painting. The fire-resistant materials were painted in accordance with the relevant construction requirements for ultra-thin the fireproof coating. The total thickness of the coating reached the upper limit of the allowable thickness of ultra-thin the fireproof coating. To avoid cracks on the dry coating surface and prevent poor adhesion between the coating layers, the thickness of each new layer was suitably decreased after the total coating thickness reached $2 \mathrm{~mm}$. Moreover, the total coating thickness was measured multiple times to ensure that it was $\leq 3 \mathrm{~mm}$.

To satisfy the thickness requirements of China's relevant criterions on ultra-thin the fireproof coating [21], the coating thickness was calculated with the help of a split-type MC-2000D coating thickness gauge (Kedian, China) that measures coating thickness by detecting magnetism between the probe and the steel, with a measurement range of $10-9,000 \mu \mathrm{m}$.

\subsection{Test Methods}

The heating and loading of the specimens were conducted in the Structure Test Center of Jilin Jianzhu University. The test equipment comprised two parts: a modular rectangular fire test furnace and a 1,000 ton press (Figure 4a). The test furnace was allowed to have maximum planar dimensions of $4 \mathrm{~m} \times 3 \mathrm{~m}$ and could be assembled to three different sets of dimensions of $3 \mathrm{~m} \times 2 \mathrm{~m} \times 1 \mathrm{~m}, 3 \mathrm{~m} \times 2$ $\mathrm{m} \times 1.65 \mathrm{~m}$ and $3 \mathrm{~m} \times 1 \mathrm{~m} \times 1 \mathrm{~m}$, as appropriate. Given that a 1,000 ton press was required in the tests, the test furnace was reassembled to dimensions of $3 \mathrm{~m} \times 1 \mathrm{~m} \times 1 \mathrm{~m}$, with the upper and lower steel frames re-customized. The fire test furnace had a maximum working temperature of $1,200{ }^{\circ} \mathrm{C}$.

The fire test furnace should be monitored at all times during the tests so as to guarantee that the temperature of furnace increased on the basis of the ISO 834 criterion temperature-time curve [24]. The parameters measured were the specimen cross-sectional temperature, specimen deformation (axial deformation), and fireproof level. The test furnace included a heating device, that comprised a total of 12 heating plates. The furnace temperature was controlled to be in light with ISO 834 criterion temperature-time bight by adjusting output power about each heating plate. The main softwarecontrolled hardware comprised a TCW-32A/B intelligent temperature controller, RS232/RS484 level converters, and industrial control computers, with ISO 834 fire-resistance test capabilities. Moreover, a smoke evacuation device was installed to remove pungent odors generated during the tests (Figure $4 \mathrm{~b}$ ).

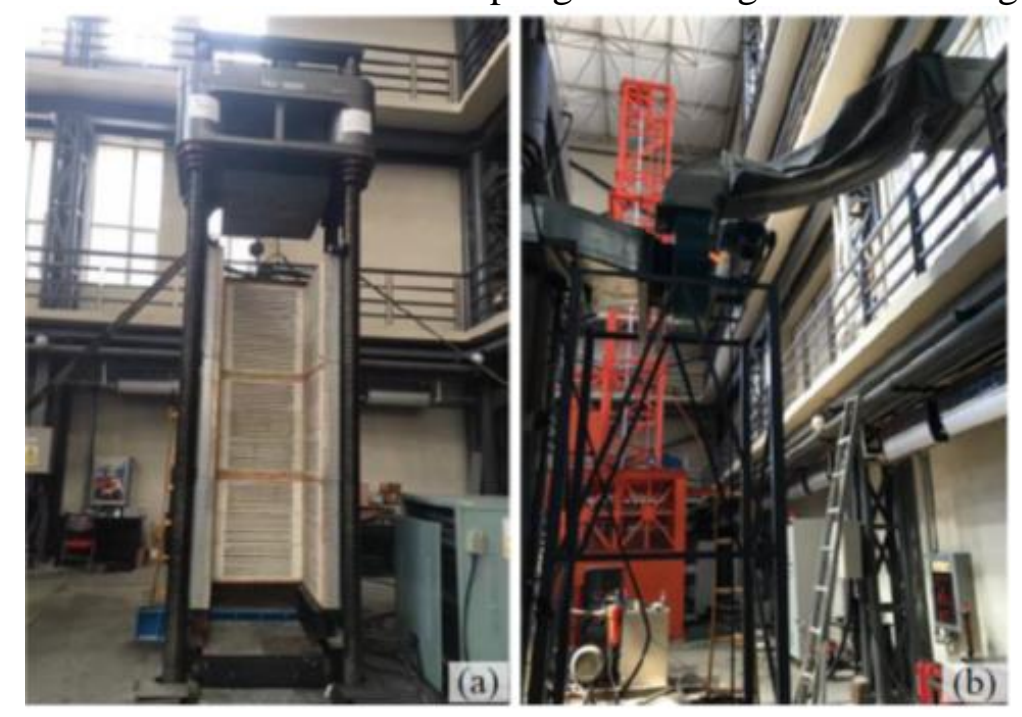

Figure 4. Flame system (a) Full sight of the fire test smelter;

(b) Flame evacuation device

Figure 5 presents a curve of measured furnace temperature $\mathrm{T}\left({ }^{\circ} \mathrm{C}\right)$ with temperature rise time $\mathrm{t}$ (min), in contrast to the ISO 834 criterion time - temperature bight. The two curves coincided well 
after heating for $10 \mathrm{~min}$. The temperature increased gradually in the first $10 \mathrm{~min}$ due to electric heating, resulting in low coincidence.

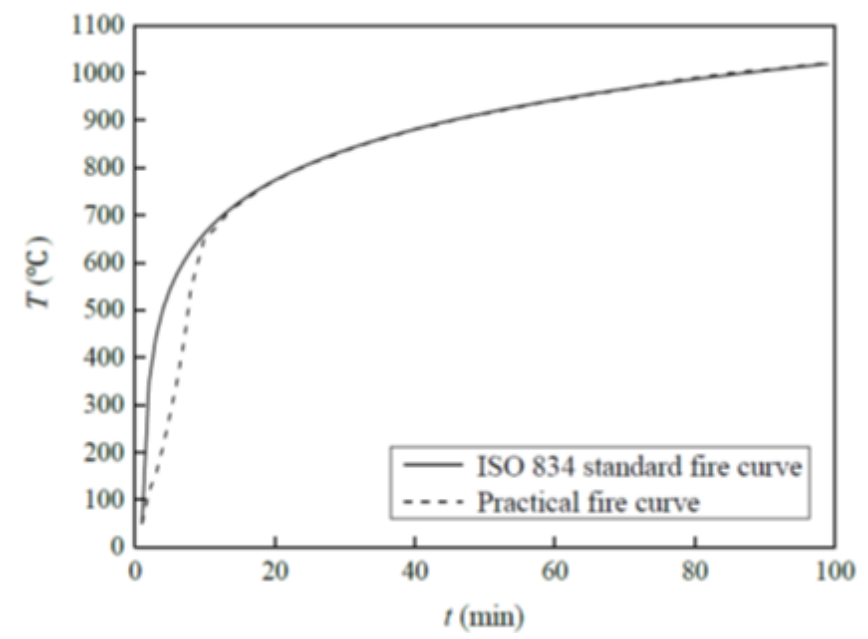

Figure 5. time - temperature bight of the fire test smelter

The test procedure comprised the following steps:

(1) Use a crane to hang a given specimen into the fire test furnace and connect the specimen to the endplates, with hinged boundary conditions applied to the both ends about samples.

(2) Connect the wires of the thermocouples and axial displacement sensors.

(3) Increase the axial load until it reaches the design load of the specimen and hold for $30 \mathrm{~min}$.

(4) Pre-heat the fire test furnace according to China's relevant criterions [27] and determine whether the furnace functions normally.

(5) Program the ISO 834 criterion time - temperature bight in the control system prior to the test such that the control system will automatically control the output power of each heating plate. This step is required because the fire test furnace was an electric heating furnace that generated a desired temperature-time curve by controlling the output power of each heating plate.

(6) Immediately collect cross-sectional temperature data and axial displacement (deformation) data when raising the temperature on the basis of the ISO 834 criterion temperature-time bight, and use the computer to achieve automatic adjustment such that the load applied to the specimen is stable;

(7) Stop the test when the axial compression displacement reaches $0.01 \mathrm{H}$ and the axial compression rate exceeds $0.003 \mathrm{H} / \mathrm{min}$ according to the definition of fireproof level in the ISO 834 criterion, in which $\mathrm{H}$ represents the sample height $(\mathrm{mm})$. This step is required because the specimen was experiencing rapidly increasing axial deformation when the specimen temperature approached the high-temperature end of the temperature-time curve.

Figure 6 illustrates a specimen installed in the fire test furnace before the test.

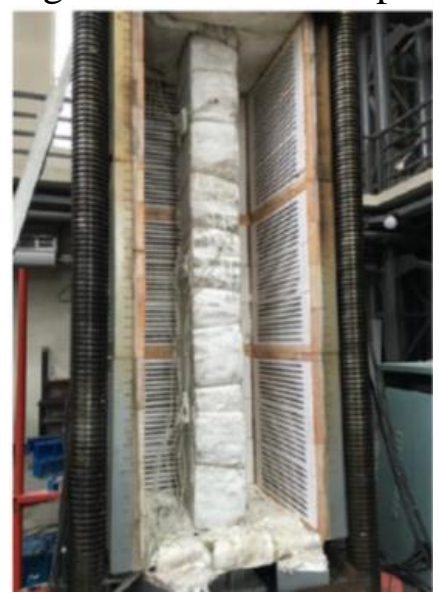

Rev. Chim., 71 (6), 2020, 437-451
Figure 6. Full view of a specimen in the fire test furnace

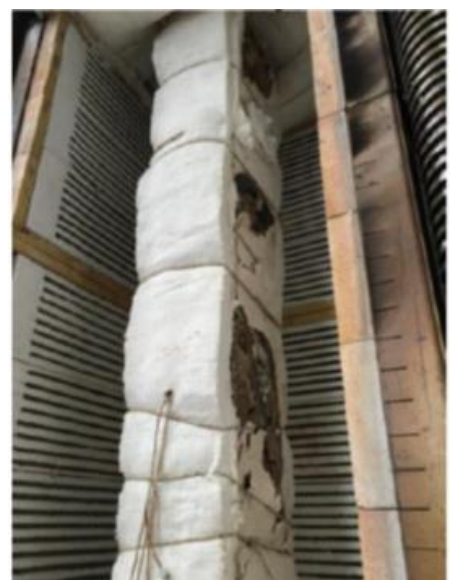

Figure 7. The fireproof coating falling off 


\section{Results and discussions}

\subsection{Failure Mode as well as Characteristics}

Fireproof coating underwent local burning when the temperature increased for approximately 5 min, with smoke evacuated from above the test furnace accompanied with pungent odors. The smoke evacuation device was turned on, and the pungent odors were present throughout the tests. The tests were stopped when the axial displacement of the specimens reached the limit values in the ISO definition of fireproof level. After opening the fire test furnace, it was observed that the the fireproof coating was swollen and had fallen off in pieces (Figure 7).

The fire test furnace was opened after the test and demonstrated that the fire-retardant fabric on the non-fire-exposed side did not fall off and was still well adhered to the steel tube. After removing the fire-retardant fabric and scraping of the the fireproof coating that was blackened by heating, the color of the steel tube was not significantly different from that before the fire-exposure test. The specimen was bent toward non-fire-exposed sides; however, the degree of deformation was not high. Owing to axial load, the utmost diversion about each specimen appeared among pillar, with overall stability failure as the failure pattern. All the specimens had local outward buckling and were in different shapes at different positions. In particular, specimens S1 and S2 were CFSST columns with two opposite sides exposed to fire; they exhibited evident local outward buckling in the upper fire-exposed parts; they also exhibited local outward buckling at the same height on the non-fire-exposed sides, with the degree of outward buckling similar to that on the fire-exposed sides. S3 was a hollow steel tube with two opposite sides exposed to fire that exhibited local outward buckling at one-third and twothirds height on the fire-exposed sides and local inward buckling at the same height on the non-fireexposed sides, with the degree of outward buckling similar to that of inward buckling. S4 was a hollow steel tube with one side exposed to fire that demonstrated local outward buckling at half the height on the exposed side of the fire and local inward buckling at the same height on the side which is not exposed to fire, with degrees of outward buckling similar to that of inward buckling. S5 and S6 were CFSST columns with one side exposed to fire that exhibited evident local exterior winding at half of the elevation on the fire-exposed side and exterior winding at same elevation on non-fire-exposed sides with weld cracks, with the fire-exposed side and non-fire-exposed sides having a similar degree of outward buckling. The presents of localized failure pattern of the specimens after the tests (Figure 8).

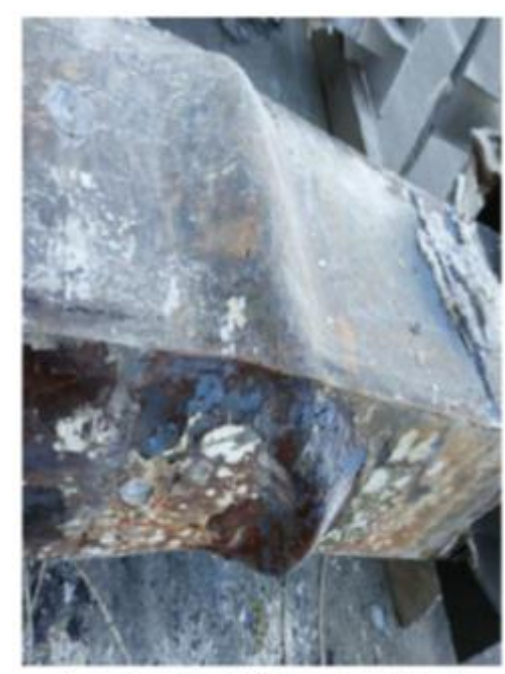

(a) Localized failure pattern of CFSST columns with two opposite sides exposed to fire

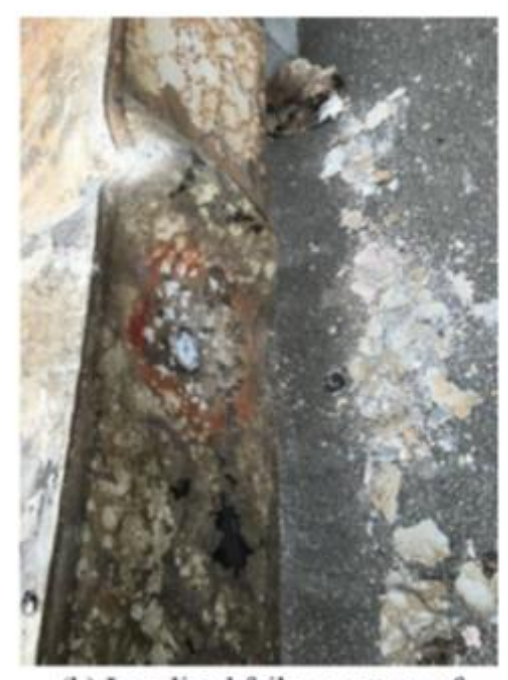

(b) Localized failure pattern of hollow steel tubes with two opposite sides exposed to fire 


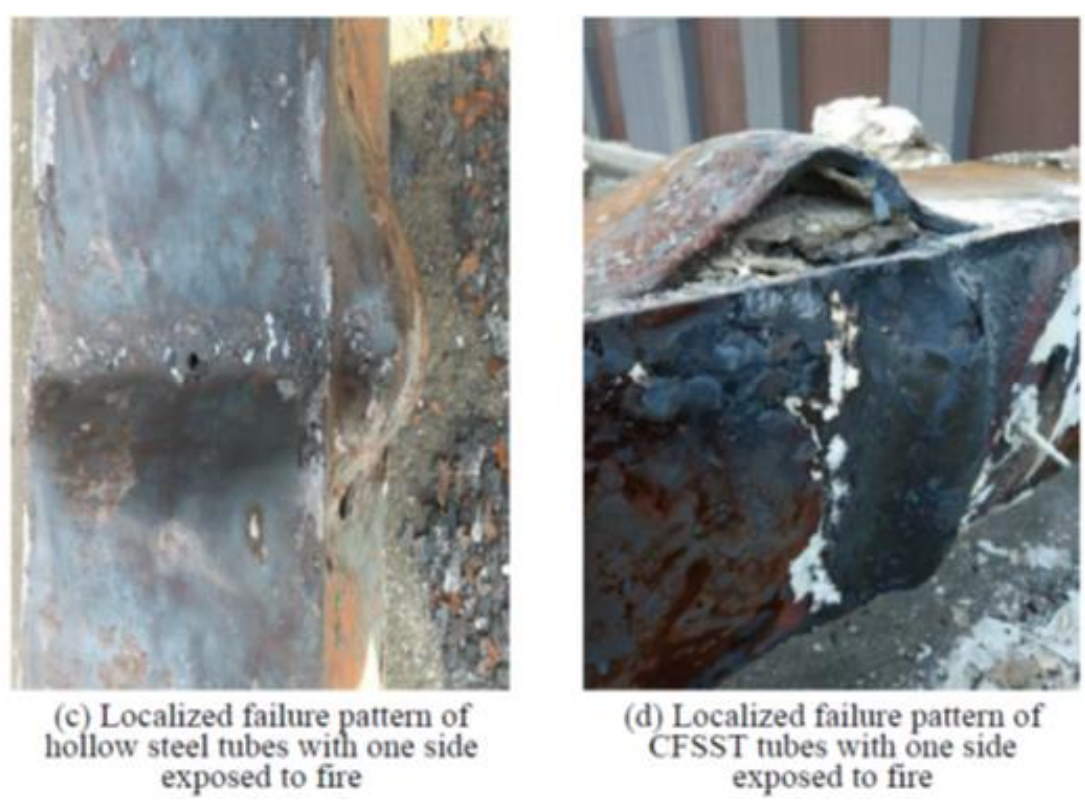

Figure 8. Localized failure patterns of test specimens

\subsection{Measurement outcomes and discussion}

\subsubsection{Temperature development}

The presents of relationship curves between temperature $(\mathrm{T})$ at the measurement point and heating time (t) for different specimens (Figure 9). Owing to the thermal insulation behavior about the fireproof coating, the heating rate about fire-exposed steel side was far lower than that of the fire test furnace. In the initial stage of heating, the heating rate was relatively high at each measurement point on the fire-exposed sides, however, relatively low at each measurement point on the non-fire-exposed sides. In the late stage of heating, the heating rate decreased at each measurement point on the fireexposed sides, however, increased at each measurement point on the non-fire-exposed sides. The temperature-time curves demonstrated an overall trend that each measurement point on the fireexposed sides had a higher heating rate than the counterpart on the non-fire-exposed sides.

As shown by the temperature fields of the steel tubes, the heating rate of the fire-exposed sides was first high and then low, exhibiting a similar variation trend to the heating rate of the fire test furnace, while the non-fire-exposed sides exhibited an opposite variation trend. For the temperature time curves at each measurement point in the core concrete, the process of temperature rising was related to the distance between the measurement point and the fire-exposed sides, that is, the shorter the distance, the greater the temperature increase. This was because concrete has a strong heat absorption capability but weak heat dissipation capability.

Moreover, the temperature fields demonstrated that specimen measurement points at different axial heights with the same horizontal coordinates had similar temperatures, indicating that both the temperature fields of the specimen and fire test furnace were uniform along the axial direction.

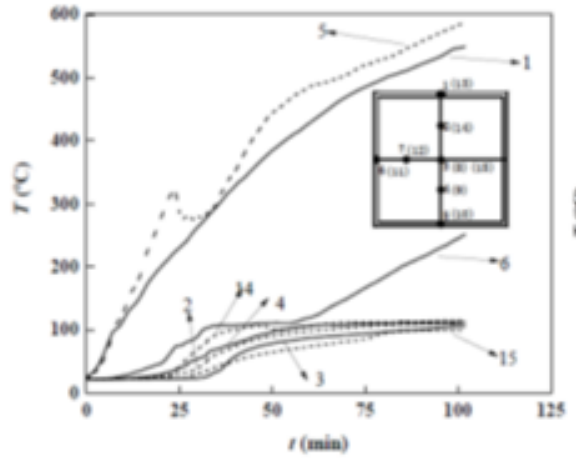

(a) $\mathrm{S} 1$

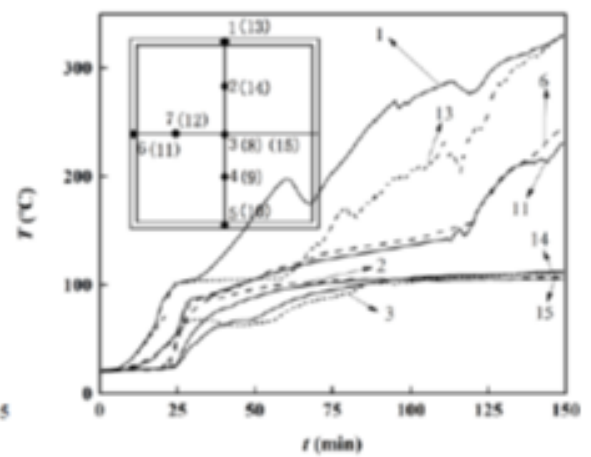

(b) S2 


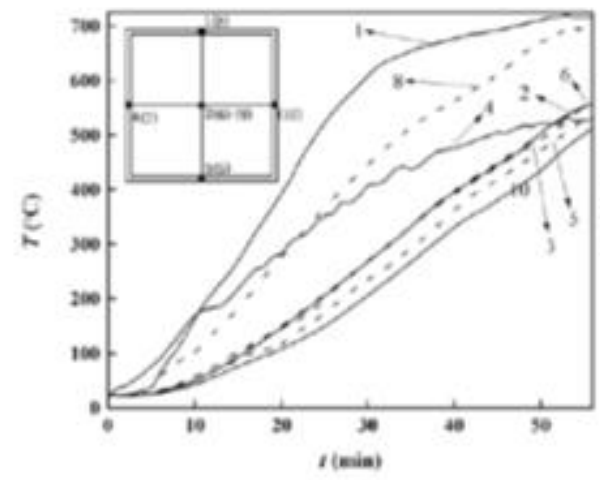

(c) $\mathrm{S} 3$

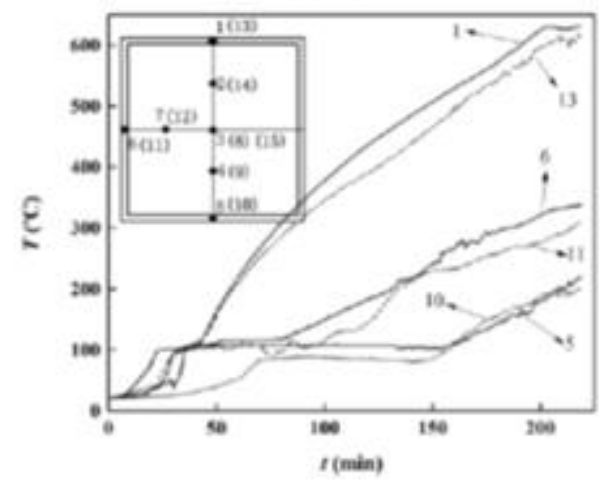

(e) $\mathrm{S} 5$

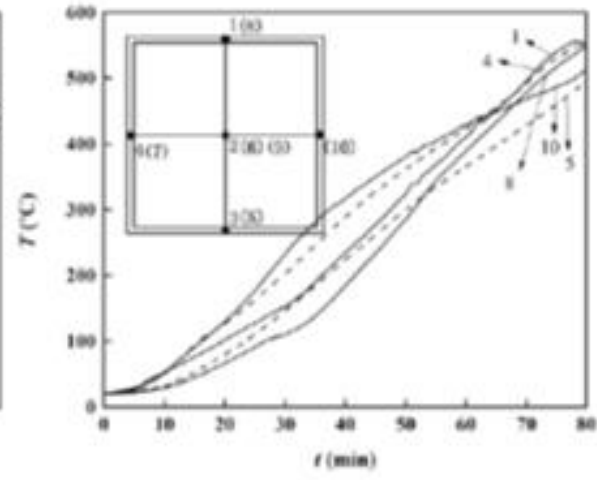

(d) $\mathrm{S} 4$

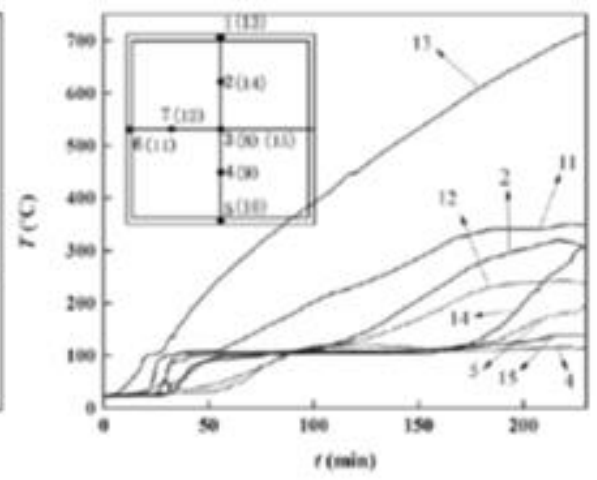

(f) $\mathrm{S} 6$

Figure 9. Relationship curves between temperature (T) of measurement point and heating time $(\mathrm{t})$ for different specimens

\subsubsection{Fireproof level}

The presents of relationship curves between axial deformation $\Delta(\mathrm{mm})$ and heating time $\mathrm{t}(\mathrm{min})$ for different specimens (Figure 10). During the whole test process, the specimens underwent axial deformation in three consecutive stages, namely initial expansion due to heating, slow decrease of deformation, and rapid decrease of deformation. In the initial stage of heating, the specimens had low cross-sectional temperatures, and therefore, a small loss of material strength at the cross sections. However, the steel underwent evident cross-sectional expansion. Therefore, the axial deformation was dominated by thermal expansion, corresponding to the deformation rise region in the $\Delta$-t curves, namely a cross-sectional stretching region. As the heating time elapsed, the cross-sectional temperatures increased, and therefore, the loss of material strength at the cross sections became more pronounced, reducing the load-bearing capacity of the specimen, thus, causing it to be axially compressed. In the late stage of heating, the loss of material strength was moderately severe due to high cross-sectional temperatures, and the specimen ultimately experienced failure under the load.

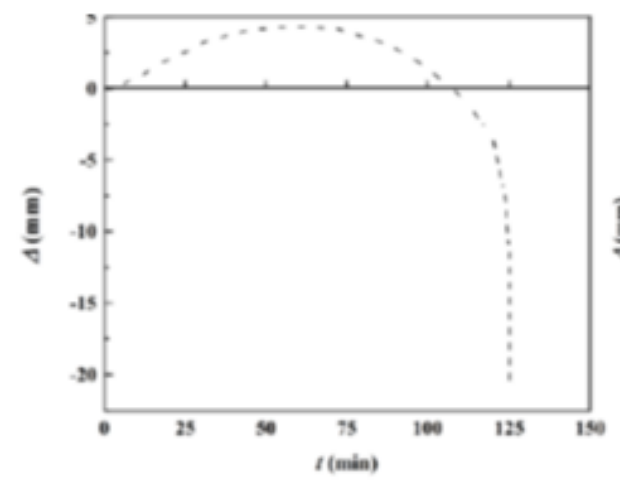

(a) $\mathrm{S} 1$

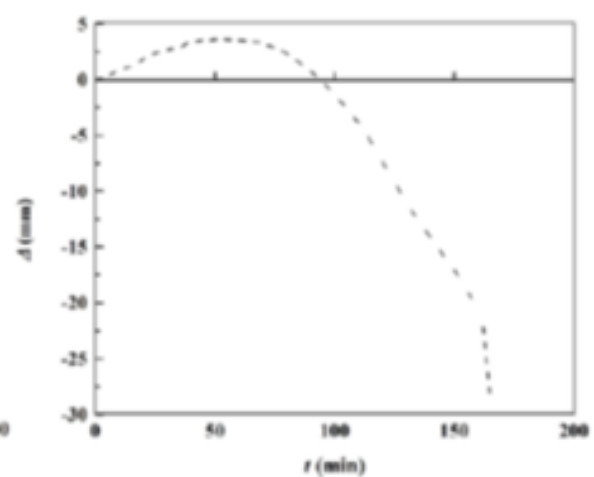

(b) $\mathrm{S} 2$ 


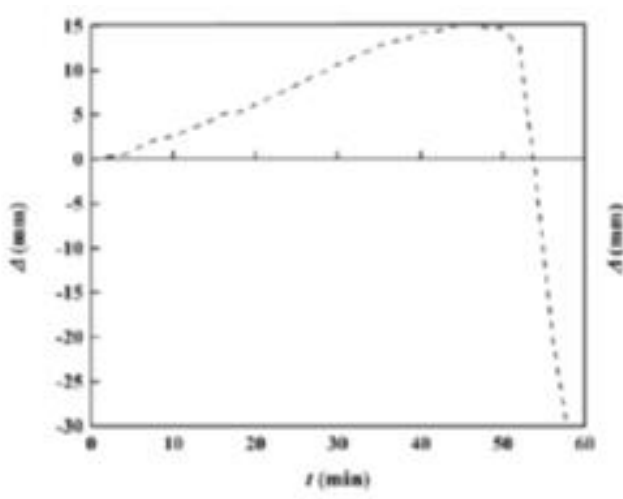

(c) S3

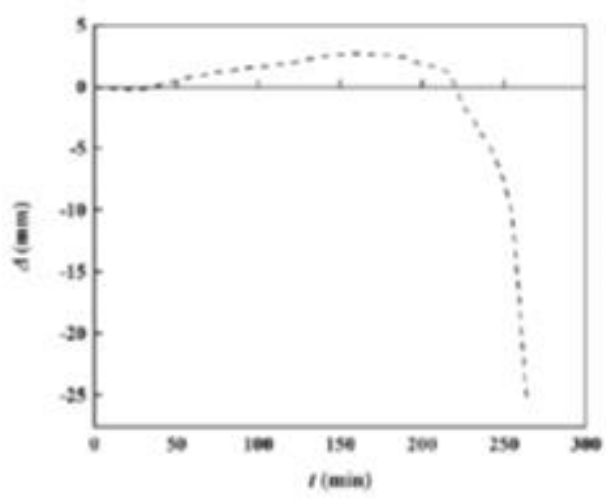

(e) S5

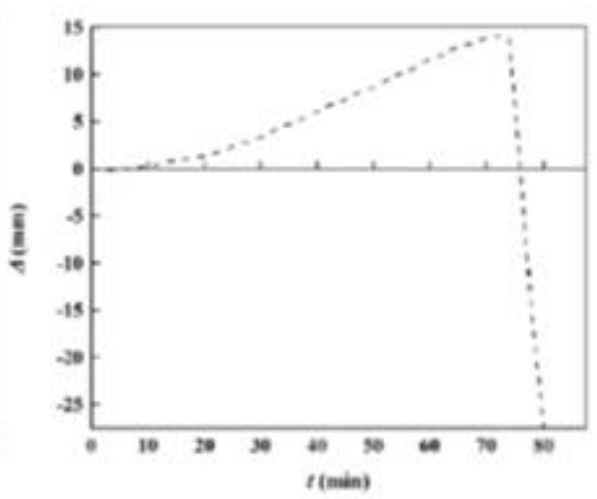

(d) S4

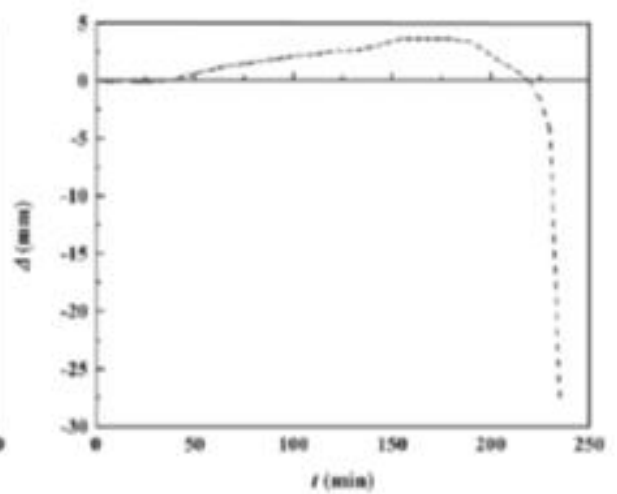

(f) $\mathrm{S} 6$

Figure 10. Relationship curves between axial deformation $\Delta(\mathrm{mm})$ and heating time $\mathrm{t}(\mathrm{min})$ of different specimens

As shown in Figures 10(a), (b), (e), and (f), the fireproof level about the CFSST columns gradually declined along with the raise in steel ratio if columns had same dimensions, steel strength, and intensity of concrete with identical fire-exposure conditions. As the steel ratio increased, thickness of steel pipe also increased. The thicker the steel pipe wall is, the larger the cross-sectional area at high temperatures, and the more severe the loss of steel strength as a result of high temperatures.

As the Figures 10(a) shows, (e), (b), and (f), samples that had the same dimensions, steel strength, and concrete strength had a lower fireproof level when subjected to two-opposite-side fire exposure than when exposed to unilateral fire. In particular, reduction in number of fire-exposed sides reduced the heat absorbed by the specimens under the same fire-exposure conditions, which would in turn decrease the thermal expansion and loss of material strength at the cross sections, thereby delaying the onset of axial compression.

As shown in Figures 10(a), (c), (d), and (f), the specimens without concrete (i.e., steel specimens) had much lower fireproof levels than the CFSST specimens. Moreover, compared with the CFSST specimens, the steel specimens experienced considerably more evident thermal expansion deformation and exhibited steep slopes in the thermal expansion deformation region of the $\Delta$-t curves, because there was no core concrete to absorb the heat, and thus, the heat was distributed along the steel tube wall resulting in rapid loss of steel strength at the cross sections. After thermal expansion deformation, the steel specimens were directly subjected to rapid compressive deformation that was also in line with the fact that failure of the steel structure may be instantaneous.

China's relevant criterions [28], provide methods to influence the model thickness about thin fireproof coating and thick the fireproof coating for steel structural columns and square steel tubes in fire-safe design; however, they do not provide a method to determine the thickness of ultra-thin the 
fireproof coating. Table 4 compared the design thickness of the fireproof coating calculated on the basis of [28] the actual thickness about ultra-thin fireproof coating in this study.

Table 4. Thickness comparison of the fireproof coating

\begin{tabular}{|c|c|c|c|c|}
\hline Specimen & $\begin{array}{c}\text { fireproof level } \\
\text { (min) }\end{array}$ & $\begin{array}{c}\text { Design thickness for thin } \\
\text { the fireproof coating } \\
(\mathbf{m m})\end{array}$ & $\begin{array}{c}\text { Design thickness for thick } \\
\text { the fireproof coating (mm) }\end{array}$ & $\begin{array}{c}\text { Actual thickness of ultra-thin } \\
\text { the fireproof coating in this } \\
\text { study (mm) }\end{array}$ \\
\hline S1 & 133 & - & 15.7 & 3 \\
\hline S2 & 162 & - & 20.8 & 3 \\
\hline S3 & 54 & 5.5 & 15 & 3 \\
\hline S4 & 78 & 6.4 & - & 3 \\
\hline S5 & 235 & - & - & 3 \\
\hline S6 & 264 & - & & 3 \\
\hline
\end{tabular}

Note: The "-" in the table shows that the model thickness about coating with the given fireproof rating exceeds the allowable range in the specifications.

Based on the data in Table 4, an analysis was conducted about the fireproof rating of the test specimens. Results indicated that equipping with the identical wall thickness steel pipe, the square steel tubes have 59.4\% lower fireproof level than the CFSST columns if subjected to two-opposite-side fire exposure, and $70.5 \%$ lower fireproof level if subjected to one-side fire exposure. With all fireexposure conditions combined, the overall fireproof level of the square steel tubes was lower by $66.75 \%$ than that of the CFSST columns.

For the same steel ratio, the fireproof level of CFSST columns when subjected to two-side fire exposure was lower than when suffered from a side fire. In particular, the fireproof rating was lower by $46.8 \%$ at a steel ratio of 0.01 and by $38.6 \%$ at a steel ratio of 0.15 . An increase in fire-exposed sides would lead to an increase in heat input to the member that would in turn lead to greater loss of mechanical functions about the concrete and steel . As a result, the fireproof level would significantly decrease, with the overall fireproof level decreasing by $42.6 \%$.

When the steel proportion increased from 0.01 up to 0.15 , the fireproof rating about CFSST columns decreased by 17.9 and 5.3\% when subjected to two-opposite-side and one-side fire exposure, respectively. With all fire-exposure conditions combined, the overall fire resistance decreased by $10.09 \%$ as the steel ratio increased from 0.01 to 0.15 . An increase in steel wall thickness would increase the cross-sectional area at high temperatures, thus explaining why the fireproof level of CFSST columns decreased with increasing steel ratio.

When applied to acquire the same fireproof level, the ultra-thin the fireproof coating could function well at a thickness considerably lesser than the design thickness specified in China's criterions for thick and thin the fireproof coating . Owing to low heat input to the CFSST pillars suffered from a side fire, flame-induced loss about material strength was small, and therefore, for this type of specimen, 3 $\mathrm{mm}$ thick ultra-thin the fireproof coating was sufficient to achieve a fireproof level above $4 \mathrm{~h}$.

\section{Conclusions}

(1) During the fire tests of specimens protected with ultra-thin the fireproof coating, the heating rate of the fire-exposed steel tube sides was considerably lower than the heating rate of the fire test furnace, indicating that the ultra-thin the fireproof coating had good thermal insulation performance and could effectively prevent high fire temperatures from damaging the members.

(2) During the tests, the heating rate of fire-exposed sides was high, increasing rapidly in the initial stage of heating, but gradually in the late stage. An opposite trend, however, was observed on non-fire- 
exposed sides. Despite being influenced by the the fireproof coating, the steel tube sides under fire exposure exhibited a significant increase in temperature with time, with the temperature time curve resembling that of the fire test furnace. The temperature of the core concrete was dependent on the distance between the core concrete and fire-exposed sides, with temperatures decreasing with increasing distance.

(3) For specimens having the same dimensions, steel strength, and strength of concrete under the identical flame-exposure conditions, CFSST columns exhibited a inferior fireproof rating as well as increasing steel ratio within a certain range. When the steel ratio increased from 0.01 to 0.15 , the overall flame fireproof level about member declined by $10.09 \%$. A growth of steel wall thickness would lead to an increase in the steel ratio of the member that would in turn increase the crosssectional temperature of the member. Therefore, it is desirable to appropriately decrease the steel wall thickness of CFSST columns in fire-safe design to increase the fireproof level if only the demanded loading weight needs not be compromised.

(4) As a result, specimens having same dimensions, steel strength, and steel plate thickness under the same fire-exposure conditions, the fireproof level of the square steel tubes was considerably lower, by $66.75 \%$, than that of the CFSST columns, indicating superior fire-resistant performance of the square steel tubes compared with the CFSST pillars. Furthermore, flame-induced failure about CFSST pillars was regarded in a gradual manner, while the onset of fire-induced failure was sudden for the square steel tubes.

(5) For specimens having the same dimensions, steel strength, concrete strength, and steel ratio, the CFSST columns had a lower fireproof level when subjected to two-opposite-side fire exposure than when suffered from a side fire, with overall fireproof rating decreasing by $42.6 \%$. Furthermore, the number of fire-exposed sides equipped an eminent momentous influence upon the flame-resistance rating in contrast to the steel ratio. In particular, $3 \mathrm{~mm}$ thick ultra-thin fireproof coating was sufficient to ensure that the CFSST columns subjected to one-side fire exposure had a resistance rating above 4 h. In fire-safe design, it is necessary to adopt different design schemes for columns with a different number of fire-exposed sides. It is desirable to use a smaller amount of the fireproof coating to reduce the cost while meeting the requirement on fireproof level.

(6) When used in specimens of the same dimensions to generate the same fireproof level, a smaller amount of ultra-thin the fireproof coating may be required than thick and thin the fireproof coating s.

\section{References}

1. HONGYAN D , CHUANG D U , PUYANG Z. Experimental investigation of seismic behavior of new concrete-filled precast tubular column. Journal of Harbin Engineering University. 38(4):538-544, 2017. (in this case Vol.38, Issues 4, and page 538-544, year 2017)

2. HASSANEIN M F , ELCHALAKANI M , PATEL V I . Overall buckling behaviour of circular concrete-filled dual steel tubular columns with stainless steel external tubes. Thin-Walled Structures. 115:336-348. 2017. (in this case Vol.115, and page 336-348, year 2017)

3. ALI F, NADJAI A, SILCOCK G, et al. Outcomes of a major research on fire resistance of concrete columns. Fire Safety Journal. 39(6):433-445. 2004. (in this case Vol.39, Issues 6, and page 433-445, year 2004)

4. XIANG K, PAN Y C, WANG G H . Axial compression analysis of square concrete-encased concrete filled steel tubular stub columns after fire exposure. Procedia Engineering. 211:1151-1159. 2018. (in this case Vol.211, and page 1151-1159, year 2018)

5. WENJING M, WENDA W, JINGXUAN W . Performance analysis of concrete-filled square steel tubular columns with internal profiled steel under three-face fire conditions. Engineering Mechanics. 33(S1):143-149, 2016. (in this case Vol.33, Issues S1, and page 143-149, year 2016)

6. XUE Y, ZHANG S, YANG W. Influence of expanded vermiculite on fire protection of intumescent fireproof coatings for steel structures. Journal of Coatings Technology and Research. 12(2): 357-364, 2015. (in this case Vol.12, Issues 2, and page 357-364, year 2015) 
7. LINHAI HAN, LIE XU, JIUBIN FENG. Research on fire resistance limit and fire prevention design of concrete filled steel tube column. China Civil Engineering Journal. 2002(6): 6-13, 2002. (in this case Vol.2002, Issues 6, and page 6-13, year 2002)

8. EID R, PAULTRE P. Compressive behavior of FRP-confined reinforced concrete columns. Engineering Structures, 132:518-530. 2017. (in this case Vol.132, and page 518-530, year 2017)

9. LUU C H , MO Y L , HSU T T C. Development of CSMM-based shell element for reinforced concrete structures. Engineering Structures, 132: 778-790, 2017. (in this case Vol.132, and page 778790, year 2017)

10. GUANGYONG WANG, CANGHU QIU, LI WANG, GENGYUAN Z. Research about flame performance about steel tube frame pillar made of concrete. Building Structure. 48(2): 88-92, 2018. (in this case Vol.48, Issues 2, and page 88-92, year 2018)

11. YI LI, XIAOXIONG ZHA, JINGTAO WANG. The Significance of Boundary Condition on Fireproof of Steel Tubular pillar made of concrete. Journal of Harbin Institute of Technology. 37: 417420, 2005. (in this case Vol.37, and page 417-420, year 2005)

12. CHEN Y H , CHANG Y F , YAO G C. Experimental study on performance of reinforced concrete column after fire. Fire Safety Journal. 44(5): 741-748, 2009. (in this case Vol.44, Issues 5, and page 741-748, year 2009)

13. LU H, ZHAO X L, HAN L H. Fire performance about steel tube high-strength self-compacting concrete short pillars. Journal of Constructional Steel Research. 65(10-11): 1995-2010, 2009. (in this case Vol.65, Issues 10-11, and page 1995-2010, year 2009)

14. ZHAO B, CHEN Z, ZHENG P. Fire resistance test of ALC board insulation SCFRT column. Journal of Tianjin University. 50(9): 931-938, 2017. (in this case Vol.50, Issues 9, and page 931-938, year 2017)

15. RUSH D, LANGE D. Vulnerability assessment of concrete columns in fire Tisova fire test. Engineering Structures. 150(1): 537-549, 2017. (in this case Vol.150, Issues 1, and page 537-549, year 2017)

16. HAN L H, ZHAO X L, YANG Y F, FENG J B. Laboratorial research and calculation of fire resistance of hollow steel pillars made of concrete. Journal of Structural Engineering. 129(3): 346-356, 2003. (in this case Vol.129, Issues 3, and page 346-356, year 2003)

17. HAN L H, YANG Y F, XU L. An experimental study and calculation on the fire resistance of concrete-filled SHS and RHS columns. Journal of Constructional Steel Research. 59(4): 427-452, 2003. (in this case Vol.59, Issues 4, and page 427-452, year 2003)

18. HONG S, VARMA A H. Analytical model about flame performance of steel tube compression pillars made of concrete. Journal of Constructional Steel Research. 65(1): 54-69, 2009. (in this case Vol.65, Issues 1, and page 54-69, year 2009)

19. EAMON CD, JENSEN E. Reliability analysis about reinforced concrete pillars suffered from flame. 62(3): 221-229, 2013. (in this case Vol.62, Issues 3, and page 221-229, year 2013)

20. EAMON CD, JENSEN E. Reliability analysis of reinforced concrete beams exposed to fire. Journal of Structural Engineering. 139(2): 212-220, 2013.(in this case Vol.139, Issues 2, and page 212220, year 2013)

21. ***Ministry of Housing and Urban-Rural Development of the People's Republic of China (MOHURD ). GB14907-2002. Fire resistive coating for steel structures. Beijing: China Architecture \& Building Press. 2002.

22. CHEN C K, ZENG J W , SHEN B Y. Experimental Investigation on Fire Response of Steel Plate with Ultrathin Intumescent Coatings. Procedia Engineering, 52(Complete): 31-36, 2013. (in this case Vol.52, Issues Complete, and page 31-36, year 2013)

23. LIU BIN, ZHANG D Z. Preparation and Properties of Ultrathin Waterborne Intumescent Fireproof Coating for Steel Structures. Paint \& Coatings Industry. 41(1): 44-47, 2011. (in this case Vol.41, Issues 1, and page 44-47, year 2011) 
24.***International Organisation for Standardisation. ISO 834-1. Fire resistance tests-elements of building construction. Part 1: general requirements. Geneva. International Organisation for Standardisation Press. 1999.

25.***Ministry of Housing and Urban-Rural Development of the People's Republic of China (MOHURD). GB50081-2002. Standard for test method of mechanical properties on ordinary concrete. Beijing. China Architecture \& Building Press. 2002.

26.***Ministry of Housing and Urban-Rural Development of the People's Republic of China (MOHURD). GB/T228- 2002. Metallic materials-Tensile testing at ambient temperature. Beijing. China Architecture \& Building Press. 2002.

27.***Ministry of Housing and Urban-Rural Development of the People's Republic of China (MOHURD). GB/T 9978-1999. Fire-resistance Tests-elements of Building Construction. Beijing. China State Bureau of Quality and Technical Supervision Press. 1999.

28.***Ministry of Housing and Urban-Rural Development of the People's Republic of China (MOHURD). GB50016 -2014. Code for Fire Protection Design of Buildings. Beijing. China Standard Publishing House. 1999.

$\overline{\text { Manuscript received: } 17.03 .2020}$ 